\title{
ENSEÑAR SEXUALIDADES, APRENDER SUBJETIVIDADES: UNA REFLEXIÓN DESDE EL CONTEXTO EDUCATIVO VENEZOLANO ${ }^{1}$
}

\author{
César Augusto Pérez Jiménez \\ Profesor de Psicología Educativa de la Universidad del Zulia \\ Maracaibo, Venezuela \\ Luis Enrique Meléndez-Ferrer \\ Profesor de Investigación Educativa de la Universidad del Zulia \\ Maracaibo, Venezuela
}

Recibido 13-X-2008 • Aceptado 12-V-2009 • Corregido 20-V-2009

Resumen: Pensar en educación conlleva pensar en actores, escenarios y contextos sociales. La sexualidad, la enseñanza, el aprendizaje, la vivencia y la corporeidad juegan un papel preponderante en la formación de la conciencia ciudadana para la participación en una sociedad plural y diversa. Ante la urgente necesidad de reflexionar sobre los discursos educativos es decisivo valorar la subjetividad como una forma de comprensión de la vida cotidiana y, en consecuencia, de la sexualidad, la ciudadanía y la inclusión. Esto conduce a repensar la educación sobre la sexualidad, a partir de las dinámicas intersubjetivas desde las cuales emerge el reto que apunta a la enseñanza y el aprendizaje de valores humanos sustentados en la crítica reflexiva sobre la vida misma. Así, los educadores y educadoras están convocados a discernir sobre la sexualidad, como un asunto cotidiano y encarnado en saberes socialmente productivos, establecidos en la comprensión subjetiva de las relaciones materiales, éticas y radicales con el mundo circundante. Este es el propósito del análisis del Sistema Educativo Bolivariano venezolano, que se hace en el artículo.

Palabras clave: Educación sexual, sexualidad, subjetividad, sistema educativo bolivariano.

\section{Introducción}

En Venezuela contamos con una propuesta educativa que forma parte de una serie de transformaciones vinculantes, que involucran distintos sectores del quehacer cotidiano nacional, a la vez que actúan como eje rector de la formación del nuevo republicano y la nueva republicana a los que aspira el espíritu socialista bolivariano. Por tanto, la formación de la conciencia colectiva, crítica y reflexiva constituye un espacio social necesario para el cambio ideológico y cultural. Valoramos, entonces, la propuesta del Ministerio del Poder Popular para la Educación (MPPE) del gobierno venezolano, el cual ha replanteado la educación nacional, mediante el Diseño Curricular del Sistema Educativo Bolivariano, que beneficia la diferencia y diversidad como base para la formación de una nueva ciudadanía con conciencia social (Venezuela, MPPE, 


\begin{abstract}
To think about education implies to think about social actors, scenes and contexts. Sexuality, education, the learning, the experience and the corporeality play a preponderant role in the formation of the citizen's conscience of the participation in a plural and diverse society. Before the urgent necessity to reflect on the educative speeches it is decisive to value the subjectivity as a form of understanding the daily life and, consequently, of the sexuality, the citizenship and the inclusion. This leads to rethink the education on sexuality, from dynamic the inter-subjective from which the challenge emerges pointing out at education and learning of sustained human values in the reflective critic of life itself. Thus, the educators are summoned to discern on the sexuality, as socially productive daily subject and embedded in knowledge, established in the subjective understanding of the material, ethical and radical relations with the surrounding world. It is the intention of the analysis of the Educative System of Venezuela that is made in the article.
\end{abstract}

Key words: sexual education, sexuality, subjectivity, educative system of Bolivarian Republic of Venezuela.
2007); la cual, aboga por una educación pluralista, transformadora y garante de la formación ética y ciudadana.

El Sistema Educativo Bolivariano (SEB) se basa en la concepción educativa de Simón Rodríguez; la cual inspira un proceso colectivo e integrador en una sociedad que actúa como una gran escuela formadora de ciudadanos y ciudadanas. Se cimienta en el pensamiento Robinsoniano, Bolivariano y Zamorano, mediante los cuales se establecen cuatro pilares para el desarrollo integral del nuevo ser social, humanista y ambientalista: Aprender a Crear, Aprender a Convivir y Participar, Aprender a Valorar y Aprender a Reflexionar (Venezuela, MPPE, 2007).

El SEB reproduce la educación bolivariana como un proceso político y socializador, creado en las relaciones escuelafamilia-comunidad, así como en la interculturalidad, la práctica del trabajo liberador y el contexto histórico-social. La educación bolivariana promueve formas para obtener conocimientos en su devenir histórico y en contextos socioculturales. Con ello, se busca fomentar la capacidad de transferir las epistemes populares y científicas para comprender los problemas sociales, políticos y ambientales en la vida cotidiana; a su vez, entiende el carácter social del conocimiento y la forma en que éstos se utilizan en las culturas. Por lo cual, los pilares son elementos que orientan los componentes de las áreas de aprendizaje y los ejes integradores que coadyuvan experiencias de aprendizaje inter y trans-disciplinarias, configurando los nuevos republicano y republicana, mediante los aprendizajes en las relaciones colectivas con su contexto histórico-cultural.

La organización del SEB parte de la conformación estructural en subsistemas educativos (Tabla 1), interrelacionados entre sí de manera flexible e integral. Con ésto, se asegura la igualdad de oportunidades y condiciones para integrar a todos y todas en los subsistemas; atendiendo la diversidad multiétnica, intercultural y pluricultural, así como las necesidades educativas especiales. Otra característica del sistema 
es el despliegue de capacidades, habilidades e intereses científico-tecnológicos en cada subsistema, tomando en consideración las necesidades-problemas en los contextos socioculturales de la Nación. Se centra, entonces, en una concepción humanista, social, ambientalista, participativa, protagónica y corresponsable del ser humano.

En ese contexto educativo, el desarrollo humano es asumido como una construcción histórica, social y cultural, que parte de la concepción inacabada de la persona, concebida de manera integral, dinámica y comprometida con una forma de aprendizaje colaborativo para el bienestar común. De este modo, la interacción social actúa como base para la formación de personalidades ciudadanas con espíritu democrático, equitativo y emancipador, donde la civilidad, como proyecto político, se constituye a partir de identidades plurales orientadas a la inclusión y participación social, para transformar las realidades culturales que protagonizamos localmente.

Desde la educación democrática, equitativa y emancipadora, se colabora con la liberación del pensamiento, partiendo de la educabilidad para la ciudadanía desde la alteridad. Esto surge de la relación tolerante, respetuosa e inclusiva sustentada en la valoración socio-cultural del otro como parte de mi mismo (cfr. Dussel, 1999; Montero, 2000, 2002; Valera-Villegas, 2002). De modo que, la acción de educar la sexualidad humana considera la atención de desafíos histórico-culturales producidos por efecto de las prácticas sociales dirigidas a la dominación ilustrada de las subjetividades; las cuales, están mediatizadas por la cultura patriarcal-masculina, vivida como consecuencia de posturas colonialistas definitorias de cierto tipo de acciones de significación cultural descritas por su carácter hegemónico, universal y totalitario del sersaber-y-hacer (Pérez y Vázquez, 2006).

Lejos defomentar prácticas educativas convencionales, según una pedagogía de mentiras bajo esquemas de domesticación social (Chomsky, 2002), es necesario dirigir la reflexión científico-social sobre discursos educativos que procuren amplificar zonas de sentido sobre lo cultural. Estos discursos valoran y comprenden las cotidianidades desde las subjetividades; por ende, la sexualidad, ciudadanía y la inclusión, basadas en las necesidades colectivas de grupos minoritarios y mayoritarios, procurando minar los imaginarios sociales sobre la educación sexual tradicional, colonialista e imperialista, centrada en la medicalización y patologización del comportamiento sexual, mediante estrictos dispositivos de control y normalización, que encarnan el orden civilizatorio moderno (Foucault, 1996, 2006).

La idea de este trabajo es esbozar reflexiones teóricas que favorezcan el debate crítico sobre nuestras prácticas pedagógicas en materia de sexualidad. Esta discusión, más que fundarse en datos empíricos limitativos, procura crear intersticios para entender la educación sexual desde la experiencia curricular venezolana; sobre todo, al momento de vivenciar una reforma educativa orientada por un sentido humanista social. Más que imponer ideas rectoras en los espacios educativos de países vecinos, se pretende fortalecer perspectivas compartidas sobre la educación sexual, como un problema común de las realidades educativas latinoamericanas, deseando reforzar que la formación cívica desde la sexualidad es un acto de alteridad y corporeidad que implica prácticas de interacción social para la convivencia democrática.

Dichas líneas no pretenden convertirse en un modelo final sobre la educación sexual; en todo caso, actúa como excusa para debatir sobre tópicos de urgente atención en la construcción de naciones democráticas, equitativas y tolerantes. Tal educación contrae significados, legados y vaivenes culturales e históricos sobre nuestra vida en sociedad, que han reforzado nuestra visión totalitaria en cuanto a las identidades ciudadanas. Por tanto, vale atender la educación sexual como sistema social en el que confluyen diversas 
Tabla 1

Subsistemas del Sistema Educativo Bolivariano

\begin{tabular}{|c|c|}
\hline Subsistema & Principios ideológicos \\
\hline $\begin{array}{l}\text { I. Educación Inicial Bolivariana } \\
\text { (Maternal y Preescolar: } 0 \text { a } 6 \text { años) }\end{array}$ & $\begin{array}{l}\text { El ser humano es un sujeto de derecho y ser social integrante de } \\
\text { una familia-comunidad, con características personales, socia- } \\
\text { les, culturales y lingüísticas propias. } \\
\text { La persona aprende en un proceso constructivo e integrado en lo } \\
\text { afectivo, lo lúdico y la inteligencia, garantizando su desarrollo } \\
\text { integral. } \\
\text { Inicia la formación en hábitos, habilidades, destrezas, actitudes } \\
\text { y valores basados en la identidad local, regional y nacional. } \\
\text { Ésto se realiza mediante el despliegue de potencialidades e, } \\
\text { igualmente, en el pleno ejercicio de sus derechos como persona } \\
\text { en formación, atendiendo la diversidad e interculturalidad. }\end{array}$ \\
\hline $\begin{array}{l}\text { II. Educación Primaria Bolivariana } \\
\left(1^{\circ} \text { a } 6^{\circ} \text { grado: } 6 \text { a } 12 \text { años }\right)\end{array}$ & $\begin{array}{l}\text { Forma con actitud reflexiva, crítica e independiente con elevado } \\
\text { interés por la actividad científica, humanista y artística, con } \\
\text { una conciencia en pro de comprender, confrontar y verificar su } \\
\text { realidad por sí mismo y sí misma; deseando que aprendan desde } \\
\text { el entorno para que sean cada vez más participativos, protagó- } \\
\text { nicos y corresponsables en la Escuela, Familia y Comunidad. } \\
\text { Promueve actitudes para el amor y el respeto hacia la } \\
\text { Patria, con una visión de cooperación e integracionista hacia } \\
\text { Latinoamérica, el Caribe y el mundo. } \\
\text { Reafirma hábitos de higiene colectiva e individual, inclu- } \\
\text { yendo los que favorezcen la salud preventiva e integral y los } \\
\text { forma para la vida de acuerdo con los fines y preceptos de la } \\
\text { Constitución Nacional. } \\
\text { Desarrolla la conciencia histórica, como plataforma para cons- } \\
\text { truir una nueva sociedad. }\end{array}$ \\
\hline $\begin{array}{l}\text { III. Educación Secundaria Bolivariana } \\
\text { (Liceo Bolivariano, de } 1^{\circ} \text { a } 5^{\circ} \text { año; } \\
\text { y Escuela Técnica Robinsoniana y } \\
\text { Zamorana, de } 1^{\circ} \text { a } 6^{\circ} \text { año: } 12 \text { a } 19 \\
\text { años) }\end{array}$ & $\begin{array}{l}\text { - Intenta la formación integral, atendiendo a fines y principios } \\
\text { nacionales, dando continuidad a estudios primarios y permi- } \\
\text { tiendo la incorporación al proceso productivo social, al mismo } \\
\text { tiempo que orienta para la prosecución de estudios superiores. } \\
\text { El Liceo forma con conciencia histórica e identidad venezolana, } \\
\text { desarrollando capacidades y habilidades para el pensamiento } \\
\text { crítico, cooperativo, reflexivo y liberador, que permita, median- } \\
\text { te la investigación, contribuir a la resolución de problemas } \\
\text { tanto de la comunidad local, regional como nacional, de manera } \\
\text { corresponsable y solidaria. } \\
\text { Construye conocimientos y despliega potencialidades para la } \\
\text { cooperación, la práctica de la economía social solidaria y el } \\
\text { manejo de relaciones de producción social, las cuales fortalecen } \\
\text { el accionar del estudiantado con responsabilidad social y com- } \\
\text { promiso patrio. } \\
\text { La Escuela técnica forma el desarrollo endógeno, fomentando } \\
\text { tanto habilidades, destrezas, valores como virtudes que apoyen } \\
\text { esta orientación; así mismo, propicia el pensamiento crítico, } \\
\text { reflexivo, humanista, liberador y ambientalista. }\end{array}$ \\
\hline
\end{tabular}




\begin{tabular}{|l|l|}
\hline Subsistema & \multicolumn{1}{c|}{ Principios ideológicos } \\
\hline V. Educación Intercultural & $\begin{array}{l}\text { Atiende la educación integral de pueblos y comunidades afro- } \\
\text { descendientes e indígenas, desde contextos de diversidad cultu- } \\
\text { ral, teniendo como punto de partida la educación propia. } \\
\text { Fortalece un ser social que mantenga la identidad étnica- } \\
\text { cultural, la cosmovisión, valores y espiritualidad; así como, la } \\
\text { construcción de conocimientos y saberes, la transmisión de tra- } \\
\text { diciones ancestrales en una sociedad democrática, multiétnica } \\
\text { y pluricultural. } \\
\text { Apoya la conciencia histórica y la unidad de la Nación venezo- } \\
\text { lana. }\end{array}$ \\
$\begin{array}{l}\text { VI. Educación de Jóvenes, Adultos } \\
\text { Robinson } 1 \text { y } 2 \text { y la Misión Ribas: } \\
\text { mayores de } 18 \text { años) }\end{array}$ & $\begin{array}{l}\text { Comprende las opciones: presencial, semi-presencial o por } \\
\text { encuentros y misiones (Robinson y Ribas). } \\
\text { Desarrolla cultural, social y productivamente a jóvenes, adultos } \\
\text { y adultas, por medio de la formación de conocimientos científico- } \\
\text { tecnológicos; así como, de habilidades, destrezas y valores que } \\
\text { permitan interactuar con el medio, identificarse con su Nación, } \\
\text { actuar con conciencia social y participar organizadamente en } \\
\text { la construcción de una sociedad, acorde con los principios de la } \\
\text { Nación, enmarcada en la visión de la realidad latinoamericana, } \\
\text { caribeña y universal. }\end{array}$ \\
\hline
\end{tabular}

Fuente: Venezuela, MPPE (2007)

estructuras que armonizan dinámicas educativas sobre el sentido intersubjetivo de lo humano, en oposición a la perspectiva anatómico-fisiológica que la ha explicado según conceptos encajonados en la caracterización biocéntrica de la sexualidad.

\section{Positividades educativas coloniales sobre sexualidad}

En Venezuela se ha iniciado una ruptura con los discursos educativos de dominación inspirados en los principios modernos-coloniales, que enfatizan la producción de conocimientos encarnados en una matriz colonial de poder que ratifica al hombre blanco occidental, como modelo de una sana sexualidad (Castro-Gómez y Grosfoguel, 2007; Mignolo, 2007). Tales discursos se han legitimado por los aparatos ideológicos del Estado, fosilizándose en las prácticas educativas y han sido herencia de prácticas colonialistas que vivió la América Latina desde el antiguo régimen.
Lo anterior, legitimó los idearios educativos, sociales, políticos, económicos, jurídicos e históricos, girando en torno a una sola idea: la formación de un ciudadano universal respondiente a los preceptos napoleónicos y borbónicos. Esto se concentró en el ocultamiento y silenciamiento, tanto de la diferencia como de la diversidad, mientras se exhibía el Patriarcado como práctica legitimadora de socialización, en la que los cuerpos subjetivos y los ciudadanos, respondían al imaginario del hombre blanco occidental. Por tanto, mujeres, niños, niñas, ancianas, ancianos, discapacitados $\mathrm{y}$ discapacitadas, así como cualquier otro que fuese un des-poseedor de bienes, no era considerado parte del colectivo ciudadano, no formaba parte de los beneficios de la civilidad regida por la igualdad de los hombres ante las leyes (Vázquez, 2005). Obviamente, cualquier jactancia de diferenciación sexual en la educación formal e informal que no respondiera a estos prinzcipios era legalmente prohibida, silenciada y probada como inexistente. 
En este orden de ideas, la educación contemporánea se desarrolla en un marco cultural, social e histórico sustentado en prácticas hegemónicas, traducidas en la determinación inequívoca de poderosas estructuras de conocimiento cosechadas desde la Ilustración. Situación que se traduce en un colonialismo educativo, pues se sacralizan diversos dispositivos de control derivados de la racionalidad tecnocrática inscrita en el pensamiento modernooccidental. De allí que, entre los propósitos curriculares venezolanos, se promueva la lucha contra los valores del sistema capitalista que han penetrado los discursos educativos latinoamericanos para diseñar un proyecto universal de subjetividad, ciudadanía y sexualidad (Venezuela, MPPE, 2007).

Carnoy (1977) sugiere que la educación respondiente a las relaciones de mercado propuestas por la economía capitalista, se inscribe en un modelo imperialista. Esta educación se fundamenta en la opresión de actores sociales, provocando la construcción de una cultura del silencio, donde se racionaliza lo irracional y se aceptan las estructuras opresivas. Según este parecer, la educación funciona como un sistema de esclavitud ideológico-social, empleando el adoctrinamiento para ocultar la libertad de pensamiento; obviando así, los síntomas socialmente producidos en las relaciones asimétricas. Por su parte, Freire (1996) considera que la educación de aspecto colonial, se funda en la dialéctica entre oprimido-y-opresor, que produce situaciones de desventaja entre iguales y refuerza el ideario liberal entronizado en el discurso educativo.

La colonialidad educativa se circunscribe a un sistema de relaciones que enfatiza la conciencia oprimida de un pueblo, que acepta sin mayores consideraciones los dispositivos de control contenidos en los instrumentos reguladores implícitos en el discurso pedagógico (Foucault, 1992, 1999; McLaren, 2001). Esto surge de las relaciones pedagógicas creadas a partir de las positividades científicas (Lander, 2000) y su emparentamiento con la dualidad del mundo público-privado, que vive el sujeto individual configurado desde el antiguo régimen; el cual precisaba la representación del poder soberano en la figura real (Vázquez, 1999). De este modo, la ciencia social inspirada en discursos de dominación y rupturas ontológicas capaces de afianzar la dualidad cartesiana humana-social, ha procurado que la educación se estructure según el ordenamiento del desarrollo humano desde una óptica mecanicista propia de modelos evolutivos adosados a una lógica conductista.

Inspirada en la modernidad, la educación subraya el dominio del positivismo lógico en los sistemas y estructuras circulantes en las prácticas pedagógicas, olvidando su razón social: la formación de ciudadanos y ciudadanas para la vida democrática. Este modelo educativo genera productos y procesos definidos desde una visión tanto decimonónica como ascética del conocimiento, que refuerza prácticas totalizadoras de producción-consumo de bienes culturales, fundadas en el capitalismo. Con ello, la aspiración liberalista apunta a la aceptación de tales discursos por todos de una manera uniforme y con sentido universalista, subrayando el desarrollo de programas formativos traducidos en diseños instruccionales sexistas y excluyentes. Ellos enfatizan el carácter objetal e instrumental de la producción de saberes, cuyo aprovechamiento cultural se desvincula de las trayectorias históricas locales que definen el bienestar en los colectivos sociales. Esta fórmula educativa se edifica como un sistema de prescripciones científico-tecnológicas, que menoscaban las continuidades de carácter socio-cultural descriptoras de los modos de vida latinoamericanos.

Sobre la base de tales idearios mecanicistas, el hecho educativo se constituye en un eje focal para el desarrollo cultural de la sociedad y enfatiza los orígenes sociales, políticos, económicos y religiosos, traducidos en formas pedagógicas de control sobre el cuerpo, la sexualidad, el sexo, los géneros y las identidades. Esta forma societal, se 
basa en un colectivo científico que legitima un discurso sobre la vida pública, centrado en verdades naturalizadas y cosificadas, que determina el diario convivir de quienes enseñan y aprenden ${ }^{2}$. Además, cuenta con elementos objetivistas que facilitan su naturalización mediante esquemas lineales de producción curricular en las instituciones educativas (Beyer y Liston, 2001). En estos esquemas, es más relevante fortificar las teorías del conocimiento sobre el yo, debilitando la comprensión ontológica del ser y conduciendo los colectivos hacia modos de convivencia lejanos a atender tanto la diversidad como la diferencia de subjetividades desde el ser-saber-y-hacer (Pérez, 2008; Pérez y Vázquez, 2006).

El currículum venezolano que permanece en el imaginario docente colectivo establece criterios normativos para la vida pedagógica, que se traducen en prácticas de discriminación y exclusión socio-cultural y conducen a que los actores implicados se definan como sujetos dominados por la sujeción científico-disciplinar ${ }^{3}$. También, en este enfoque, las personas están hipotecadas con ortodoxias pedagógicas bio-psicosociales, que intentan patentar el modo de vida colectivo, según patrones de represión, conservadurismo, conductismo y linealidad de ideas, deseos y pasiones (cfr. Hill, 2007; Leistyna, 2007).

Con-y-desde el currículum, el conocimiento se apodera de ideologías sociales sobre la sexualidad, el sexo, los géneros y las identidades, convirtiéndolas en doctrinas de dominación y domesticación del saber social emergente de las mismas relaciones cotidianas como objeto de colonización (Chomsky, 2002; Lander, 2000; Wallerstein, 2005). Del mismo modo, se establecen patrones de conocimientos sobre la experiencia simbólico-sexual y corporal como objetos científicos desvinculados de sus implicaciones genéticas históricosociales, centrándose en una pedagogía de contenidos, así como en políticas instruccionales convertidas en didácticas asépticas y monásticas sobre el cuerpo y la cultura sexual. Esta opera con la intención explícita de escindir las relaciones sociales, controlar la doctrina de los cuerpos objetivados y subyugar las subjetividades sociales, de cara a fortalecer el ideario patriarcal-masculino imperante en nuestras sociedades latinoamericanas.

En contraposición, hay que considerar lo educativo más allá de lo didácticamente establecido sobre la enseñanza y el aprendizaje de lo sexual. Con esto se entiende que tales aspectos actúan como procesos diferenciados e interdependientes, que se debaten entre la imposición de un currículum escolar institucionalizado y la emergencia de un currículum popular construido en la calle; por ende, desde la cotidianidad de la gente. Urge, entonces, replantear los conceptos educativos en torno a la ciudadanía desde la corporeidad, subrayando con especial atención la enseñanza de la sexualidad como modo de acercamiento al aprendizaje de subjetividades. Por esto, es apremiante una acuciosa crítica sobre la educación sexual, en tanto se impone como una práctica cosificada para el ejercicio del poder.

Pensar en la educabilidad de lo sexual revela un desafío ético que conlleva analizar la diferencia y diversidad en un territorio que se funda en prácticas no-sociales (cfr. Maturana, 2002), donde la anulación "del emocionar" fortalece la discriminación en las estructuras y entramados sociales. Esto conduce a repensar la educación sexual de acuerdo con las dinámicas intersubjetivas, espacio donde el reto de enseñar y aprender valores humanos sustentados en la crítica y reflexión sobre la vida misma, sugieren que tal educación, especialmente la venezolana, enfrenta el gran desafío de vivenciar-la-vida para aprender a enseñar a co-vivir. Es decir, vivir en cooperación, armonía, respeto, solidaridad, honestidad y transparencia; sobre todo, vivir desde-ypara el sentido de lo humano, basado en la práctica de la libertad, en tanto cuidado del sí mismo como cuidado del otro (Foucault, 2003; Maturana, 2002; Pérez, 2008). 


\section{La educación sexual como práctica de saber y poder}

Comúnmente, la sexualidad se constituye en un tema prohibido y normalizado para ciertas edades, localidades, disciplinas e instituciones profesionales en la educación venezolana; sobre todo, porque se cree que algunas personas no están aptas para conocerlos. Igualmente, es entendida por tener temas mutilados en su profundidad de sentido, tergiversados en su ontología y funcionalidad cultural, reducidos a la genitalidad como aspecto definitivo del ser-sexual, depurados mediante criterios discriminantes que afectan la participación social y sesgados por enfoques tanto moralistas $\mathrm{y}$ anacrónicos, como descontextualizados.

Asumir socialmente tales presupuestos sobre la sexualidad influye en la formación de un imaginario educativo que prescribe contundentemente una pedagogía ultra-programada sobre el funcionamiento sexual. Esto se circunscribe a patrones comportamentales que determinan los roles e identidades como hombres y mujeres, consagrando así la racionalidad dominante del género sobre la dicotomía genital desvelada en las ciencias naturales y biológicas; es decir, a la dupla hombre-mujer y sus consecuentes prácticas patriarcales centradas en la supremacía masculina (Díaz, 2005; García, Cabral, Monsalve y Alarcón, 2003; Sierra, 2002). Lo expuesto, determina la concepción del currículo como modo de intervención participativa y desarrollista en las comunidades locales, tendiendo a la configuración y funcionalidad de sistemas corporales inscritos en la genitalidad producida en las relaciones binarias de género, lo que contrae adoptar prácticas pedagógicas diferenciales.

Pareciera ser que vivimos en una sociedad ajena a reconocer y profundizar reflexivamente los diversos sentidos sobre la sexualidad como atributo complejo de la condición humana (cfr. Butler, 2006). La concepción desde la modernidad sobre lo humano, enfatiza la sexualidad con fines netamente reproductivos, la profilaxis de enfermedades sexuales y el control ordenado de comportamientos sexuales según diagnósticos clínicos, como forma vigilante del cuidado del cuerpo, tal como puntualiza Foucault (1992). Ello, con el fin de perpetuar la humanidad mediante la enseñanza de lo sexual con un carácter prescriptivo, fundada en un compendio de comportamientos estandarizados ${ }^{4}$ sobre ser-saber-yhacer sexualidad en la cotidianidad.

La educación sexual tiene vigente el discurso ordenado de los cuerpos colectivos e individuales, como sostenimiento de la linealidad heteronormativa, que identifica la sociedad con la adopción de un ideario de ciudadanía basado en las características del varón blanco occidental, producido en el "lenguaje liberador" inscrito en los Derechos Humanos Universales de 1789. Este ideario se mantiene vigente en el discurso educativo venezolano, subrayando la construcción de lógicas de pensamiento científico y popular, que refuerzan significados diferenciadores de las funcionalidades sexuales centradas en el cuerpo-máquina, más no en los correlatos ético-morales generados en la intersubjetividad, suscribiendo la comprensión de la sexualidad en Latinoamérica a los órdenes implantados por el discurso bio-andro-céntrico moderno.

La formación sexual ha perseguido consolidar múltiples mecanismos sociales pautados por visiones higienizantes del comportamiento. Con esto, se resaltan prácticas manifestadas por grupos minoritarios, cuyas actividades sexuales se dan fuera de la norma médico-social establecida en el orden decimonónico de la vida sexual pública en Venezuela. Dicha educación, se cimienta sobre bases médico-psiquiátricas, que conciben la diagnosis de patologías sexuales como medida de control y asepsia social, que orienta sus intenciones a la internalización de roles normales que la sociedad exige y espera de cada sexo (cfr. Foucault, 2006, 1996; García et al., 2003).

Por asentar bases en las teorías educativas con aspiraciones más científicas, 
naturales y sanitarias, la educación sexual interactúa en el contexto latinoamericano en un marco curricular que provee una estructura teórico-metodológica promotora de una enseñanza funcionalmente orientada por el diseño, objetivos, didáctica, organización, metodología y evaluación educativas (Silva, 2001). Esto fortalece un sentido prescriptivo-conductual de la educación, requerido para mantener la conflictiva diferenciación sexual, que es demandada por el capitalismo y el patriarcado, generador de pragmatismos educativos utilitaristas para la vida pública y ciudadana (Acker, 2000). Por ello, este modo educativo excluye la enseñanza de la sensibilidad y la responsabilidad social de la sexualidad, desconociendo las relaciones existentes entre sexo-saber-y-poder, que orientan las relaciones sociales sexuadas (Foucault, 2006).

Se persigue, entonces, adentrar en discusiones que desvelen la construcción de la sexualidad, el cuerpo-sexo, la interrelación entre la diversidad y diferencia de géneros sexuados y los movimientos segregacionistas, como problemas sociales contra-hegemónicos en el contexto venezolano. Así pues, se requiere desvelar el conjunto de saberes cosificados sobre el cuerpo y las relaciones sociales, mediatizadas por dispositivos de control y vigilancia sobre diversos órdenes sociopolíticos, que responden a las dinámicas del poder, según las demandas establecidas por y para la educación como espacio político de dominación. Aspectos a tomar en cuenta, si se desea fomentar la lucha cultural por la inclusión social en Latinoamérica desde diversas perspectivas y distintos contextos.

Lo anterior conlleva varios inconvenientes sobre educación sexual en el contexto venezolano. Uno de ellos es que la política educativa sobre el sexo y la relación entre géneros, se comporta como sistema de formación estructurada, preestablecida y normativa para una vida individual, productiva, competitiva y aparentemente asexuada. En respuesta, se prevé una forma de adoctrinamiento con énfasis en la velocidad como modo de vida y en las relaciones socio-económicas de producción, que fundan la competitividad de los mercados de expresiones socio-sexuales ${ }^{5}$, teniendo las relaciones patriarcales como eje del proyecto dominador.

Otro inconveniente radica en que la formación docente se rige por economías intelectuales de los mercados del conocimiento sobre varios aspectos, tales como: el cuerpo, la sexualidad, los géneros y las intersubjetividades. Esto configura un estilo de formación centrado en la producción de sujetos como reproductores instruccionales de categorías representacionales sobre la sexualidad y funcionarios de gabinete, más que en la construcción de docentes como actores e intelectuales sociales orientados hacia una educación sexual, fundada en la libertad y la emancipación cultural de los pueblos latinoamericanos.

Los planes de formación permanente de docentes en Venezuela develan las necesidades puntuales de formación sobre los aspectos mencionados. Dichas necesidades se ocultan por efecto de alguna reforma socioeducativa, tal como se observa en otras latitudes latinoamericanas, obviándose así el propósito de la misma. Por eso, es importante que la formación sea un conjunto de acciones dadas a lo largo de toda la vida, para la reflexión y crítica sobre los acontecimientos histórico-culturales definitorios de los géneros y su interrelación en la vida pública ciudadana, así como de la conciencia histórica asociada a la sexualidad colectiva.

La formación docente en Venezuela abusa de los límites tecnocráticos desde las teorías pedagógicas con base en la adopción superficial de conceptos sexuales y corporales susceptibles de aplicación en las dinámicas de la vida escolar. Con esto, se busca controlar y vigilar los desarrollos aptitudinales y actitudinales de la esfera sexual de quienes aspiran ser formados para la vida. Lo anterior, supone un desequilibrio en la producción de saberes relacionados con el cuerpo, el sexo, la sexualidad, la interacción de géneros y las subjetividades sexuales, ya 
que lo que predomina es el sentido rentista y utilitarista de estas categorías como unidades de conocimiento científico.

En ese contexto de formación docente existe el afianzamiento de parcelas del conocimiento como contra-juego ante las políticas educativas inter-trans-disciplinarias de los saberes socialmente creados sobre lo sexual. Desde esta perspectiva, lo que importa es desarrollar el "programa escolar": su práctica y evaluación, produciendo calificaciones numéricas que abogan por resultados traducidos en conocimientos objetivos y concretos (McLaren, 2001). Este discurso pedagógico se aleja de la crítica-reflexiva sobre la teoríaacción social que sustenta los estudios subjetivos e identitarios en cuanto a los aspectos sexuales, corporales y de géneros, para centrarse en competencias desproporcionadas de conocimientos.

Es urgente reflexionar (en voz alta, audible) sobre la necesidad de transformar radicalmente los discursos vinculados a la educación sexual venezolana. Manteniendo, también, una crítica permanente sobre la vida pedagógica entre quienes enseñan y quienes aprenden, que es fundamental para la producción social y reproducción cultural de sentidos y significados sexuales que delinean la vida intersubjetiva corporal y sexual de los actores culturales. Asimismo, adoptarparadigmas pedagógicos alternativos y emergentes, lleva a los implicados a asumir sus responsabilidades culturales en la concreción de un discurso sexual-yeducativo contra-hegemónico, que facilite la crítica pública y ciudadana sobre los valores sociales, buscando la convergencia en la construcción ética de la intersubjetividad como medio para la comprensión del sersaber-y-hacer.

En suma, es necesario que la formación inclusiva de la ciudadanía se funde en la valoración de las diversidades sexuales y, sobre todo, en la interacción de las mismas en escenarios simbólicos orientados por representaciones que actúen como signos coincidentes en lo social y como estructuras dinámicas que generan la interacción "cara a cara" entre las personas. Dichas representaciones subrayan las lógicas de conocimiento sobre las sexualidades en el mundo y estimulan las mediaciones sociales en pro de comprender la psicosociodinámica de la vida cotidiana. En tal sentido, se propone una educación sexual que enfatice los modos de vida subjetivos de las sexualidades, como mediación semiótica de significados construidos en la interacción cuerpo a cuerpo, orientada a cambiar el discurso bio-andro-céntrico por otros discursos que representen las sexualidades como subjetividades sociales en la condición humana.

Es clave la enseñanza crítico-reflexi$v a$ de las sexualidades desde la cotidianidad que la produce y mantiene. Por ello, se enfatiza el análisis de sus bases orgánicas, psicológicas, político-sociales y gnoseológicas, que conduce a considerar una perspectiva fenomenológica que edifique identidades sexuales a partir de la comunicabilidad social de saberes emanados desde las intersubjetividades cimentadas en los géneros, imaginarios y prácticas simbólicosexuales. Esto comprende las sexualidades como subjetividades sociales.

\section{Las sexualidades como subjetividades sociales}

Este apartado se centra en un análisis sobre el carácter socio-científico de las sexualidades como una dimensión vital para el desarrollo humano y la comprensión de dinámicas histórico-culturales definitorias de los sentidos de alteridad y ciudadanía en la vida pública. Se resalta la intersección de tres aspectos básicos: sexualidades y ciudadanías como formas de civilidad; ello, como encuadre explicativo de una trama relacional que tiene lugar en la cotidianidad. Tales aspectos se muestran como categorías representacionales que complejizan las performatividades ciudadanas desde la reconstrucción de los sentidos sobre las sexualidades, considerando las diferencias naturales que 
surgen en las prácticas culturales de los distintos pueblos.

Es relevante plantear la acepción plural de la sexualidad, como sexualidades (cfr. Amado y Domínguez, 1998), en tanto está circunscrita a diversas formas de expresión humana. Las subjetividades sobre las sexualidades actúan como integración proyectada de lo social y, por ende, están vinculadas a diferentes modos de comprensión histórico-cultural (Elias, 2000; Maffesoli, 2005), que dibujan trayectos difusos y encontrados de ser-sexual en la cotidianidad. En esa dinámica compleja se desintegra lo privado, pues “... la sexualidad es un constructo social, que opera en campos de poder y no meramente un abanico de impulsos biológicos que o se liberan o no se liberan" (Giddens, 2004, p. 31). Sin embargo, la sexualidad y lo sexual son parte del sentido público de la vida individual, en tanto parte del entramado social. Por eso, si creemos en las sexualidades como políticas conducentes a la comprensión de identidades colectivas e individuales, puestas en diálogos intersubjetivos, su pedagogización debe reencontrarse con la producción de significados colectivos sobre lo corporal, lo sexual y los géneros, como aspectos que encarnan la trama relacional de las subjetividades. Con esto, se facilita la interpretación social de la vida pública como nodo para la construcción de identidades en distintos contextos sociogeográficos.

Foucault (2006) argumenta que la sexualidad como estructura y dinámica emerge de la cientificidad de un discurso producido desde la prohibición y el silencio. Las ciencias vinculadas a lo humano -Medicina, Psiquiatría, Pedagogía-, están consagradas a desvelar las verdades sexuales, a la vez, integradas a un proyecto científico bajo normas médicas que procuran la asepsia social y la higienización de la vida reproductiva, mediante la práctica confesionaria, que da paso a la aplicabilidad de criterios jurídicos de normalización de la vida sexual. Esto implica que aquello que figura como privado se vuelve público y es susceptible de observancia y control. La sexualidad es un asunto político, dada su pretensión de verdad sobre los seres humanos (cfr. Foucault, 1996, 2004).

El surgimiento de la scientia sexualis sugiere la posibilidad de decir la verdad sobre el sexo, lo sexual y las sexualidades, mediante la confesión en ambientes preparados para ello, como, por ejemplo: la escuela, la clínica, la familia. Sólo que esa confesión es productora de esquemas de dominación activadores de poderes legales y jurídicos que penetran los cuerpos, haciendo de éstos, sujetos dóciles de vigilancia y control (Foucault, 1992). La sexualidad, vista desde esta perspectiva ideológica, es una noción de saberes prescriptivos y normalizadores de la vida sexual privada, que la convierte junto con el sujeto en objeto de discursos pedagógicos, psiquiátricos, legales y jurídicos. Asimismo, erige una forma de tecnología política sobre las verdades sexuales que busca la profusa limpieza de la vida sexual privada y pública.

Las subjetividades sexuales son expresiones del mundo corporal y de los géneros, considerando la condición humana en sus distintas dimensiones. Tales subjetividades son construidas socio-culturalmente, por medio de la auto-producción organizada de sistemas simbólicosexuales funcionales, que sirven de escenarios para la convivencia cotidiana. En todo caso, se producen desde las prácticas naturales de socialización y asumen un carácter social, cultural e histórico que implica el desarrollo de la conciencia de vida y la ética intersubjetiva (Foucault, 2004; Louro, 2001; Spargo, 2004).

Lo expuesto hasta ahora implica una concepción plural de las sexualidades como objetos productores y reproductores de conocimientos, que deben ser bien aprendidos para activar un sentido dominante de la vida simbólico-sexual centrada en la reproducción humana. Muestra de ello es que en Venezuela existe una exacerbada proliferación de productos mediáticos, donde 
la hedonización del cuerpo actúa como ícono central de una semiosis social constituida en un enclave de dominación sobre el cuerpo, que está mediada por dispositivos tecnológicos implícitos en la politización y economía de las pasiones (Foucault, 2004, 2006; Garcés, 2005).

En vías de la reflexión pedagógica, la tendencia tradicional sobre la educación sexual enfatiza la sexualidad como un modo de control sobre la vida socio-sexual de las personas involucradas en los contextos educativos, pues afecta tanto a estudiantes como a docentes: a los primeros por ser objetos de control y a los segundos por ser sujetos de control y, a su vez, objeto de control de otros. Esta orientación se traduce en la dinámica saber-poder, que activa el dispositivo de alianza, que habla de vinculaciones socio-sexuales mediante “... un sistema de reglas que definen lo permitido y lo prohibido, lo prescrito y lo ilícito" (Foucault, 2006, p. 112). Basta con revisar los contenidos curriculares que impregnan los programas educativos nacionales para constatar la secuencia ordenada de saberes derivados de las ciencias biológicas y psicológicas sobre el ordenamiento de los sexos y los géneros en un modo binario, para entender las subjetividades incluidas en el diseño curricular que se implementa en las instituciones educativas de la nación venezolana. Desde esta perspectiva, el sujeto moderno es enfatizado mediante las lógicas educativas lineales derivadas de la ciencia universal y se proyecta en las ciencias pedagógicas mediante la feminización del ejercicio de la docencia. Además, el espíritu pedagógico del SEB refuerza la intersección médico-psico-pedagógica que debate sobre las hegemonías científico-técnica y gerencialorganizativa vigentes (Pérez de Lara, 2000). Por esto, se definen acciones didácticas basadas en dualidades y linealidades sobre la vida humana.

La pedagogización contiene prescripciones necesarias para escindir los cuerpos y las objetividades sociales e individuales, mediante formas establecidas de discursos ordenados sobre anatomía y fisiología humana. Con esto se deja de lado la comprensión de las identidades que, lejos de ser únicamente sexuales, se acunan en lo sexual para desvelar los modos subjetivos de ser persona en lo social (Butler, 2006). Es indispensable cuestionar las certezas surgidas de la vocación normalizadora de la educación sexual (Louro, 2001), orientando las interrogantes asociadas hacia el entendimiento de necesidades socialmente vinculantes, que se producen en la interacción social entre personas en la vida pública. La educación de las sexualidades depende de las formas de subjetivación que le impregna cada actor y, en consecuencia, se hace colectiva; por ello, es necesario elevar la organización en la que convergen los modos de socialización, fundamentados en una ontología relacional en el contexto cultural venezolano ${ }^{6}$.

Finalmente, la orientación sobre la concepción y la pedagogía en torno a los significados de las sexualidades estriba en fortalecer la construcción social de subjetividades e identidades colectivas y personales, en el marco de un sinfín de prácticas sexuales. Esto implica la actividad sígnica en actos representacionales, cuya función inicial dibuja límites permeables en la vida social de las personas ${ }^{7}$. Dichas prácticas ajustan la vida colectiva en torno a la diversidad y diferencia, lo que colinda con las dinámicas sexuales, corporales y de géneros, como aspectos rectores para entender el ser-saber-hacer de las personas implicadas en la educación bolivariana venezolana, considerando sus dimensiones ontológicas e histórico-culturales. Allí, precisamente, se conciben, producen y practican las sexualidades, integrando la vinculación ser-saber-y-hacer-sexualidades.

\section{Cuando la educación sexual implica aprender subjetividades o ideas para no concluir}

La educación ha tomado ciertos rumbos distintivos en la práctica cotidiana, desde una reflexión teórica que persigue 
la renovación socio-cultural. Siguiendo las ideas de Bernstein (1998), la educación es un conjunto estructural de códigos implicados con-y-en la gramática del poder, considerada como condición para la producción, reproducción y transformación de la cultura. El proceso educativo configura identidades como parte de los signos que ocurren al exterior- interior de los actos comunicacionales. Por tanto, se cree que lo educativo implica un amplio radio de acciones generadas en la estructura social venezolana, por lo que cualquier acto comunicativo-interactivo procura rasgos pedagógicos diferenciadores, constituyéndolos en espacios constructivos de identidades.

Educación y pedagogía (sobre las sexualidades) conllevan significados que superan los límites teóricos tradicionales en las epistemes científicas y populares en la conciencia colectiva de las personas involucradas en la educación bolivariana venezolana. De modo que, procuramos profundizar en las relaciones sociales como proceso-producto de actos semióticos que definen su estructura dinámica y compleja. En este cuerpo estructural, emerge la atención de las subjetividades en una interconexión de prácticas sociales que se despliegan como una urdimbre fundamental para edificar la interacción social de cara a la formación de la conciencia colectiva y al radicalismo ético orientador de la nueva humanidad social (McLaren y Jaramillo, 2006). Lo que consideramos educación, en nuestro contexto educativo nacional, implica un debate crítico de las ideologías rectoras del globalismo capitalista, así como una comprensión radical de la teoría cultural y de la economía política, “... a fin de considerar de modo más crítico la formación de intelectuales e instituciones dentro de las formas actuales del movimiento de la historia" (McLaren, 2001, p. 144).

La enseñanza de las sexualidades, como aspecto que focaliza la construcción de identidades, ha sido abordada en diferentes contextos educativos desde una perspectiva bio-céntrica. Dicho acto pedagógico considera que el cuerpo humano es un sistema operatorio constituido por órganos, cuya adecuación funcional determina el bienestar personal y, a su vez, concibe la salud como sinónimo de ausencia de enfermedad. Con ello, la intención de la educación sexual describe, comprende y explica la sexualidad, el cuerpo y las relaciones entre los géneros; pero, sobre todo, persigue sanearla y normalizarla, a fin de evitar la proliferación de pasiones desorientadas que desembocan en un enjambre de prácticas socio-sexuales desmedidas y sancionadas, para lo cual es necesaria una buena educación (Foucault, 2006).

En contraposición, abogamos por una educación de las sexualidades que provea a los colectivos sociales nacionales una enseñanza orientada a fortalecer racionalidades subjetivas e identidades expresadas en la diferencia y la diversidad. Nuestra propuesta es sobre la crítica de los planes educativos que limitan el ser-sexual, de cara a silenciar las subjetividades sexuales, y sobre el reto que esto significa para la activación pedagógica de la formación sexual en el SEB. Ello conlleva el conocimiento sobre la existencia de personas con diferentes religiones, atributos físicos, nacionalidades, prácticas sexuales, costumbres, ritos, colores de piel y un largo etcétera, que no pretende enmarcar la amplitud ontológica de quiénes somos en este mundo de relaciones. A la vez, estimulamos el pensamiento crítico-reflexivo sobre la vida sexual, la intimidad, la reproducción y la afiliación mediada por la afectuosidad entre las personas, porque en la interacción se crea la simbolización de los géneros como mediadores semióticos para comprender su/ nuestra vida socio-sexual.

De este modo, se proponen algunos señalamientos para reflexionar sobre la educación contextualizada, que favorezcan el aprender las sexualidades desde la intersubjetividad dialógica; o sea, desde las relaciones sociales. En estas interacciones, las personas que se junten armónicamente 
a focalizar sus prácticas en la participación activa, lo hacemos en pro de construir una conciencia pluralista, capaz de confrontar las ignorancias encarnadas en las semiósis colectivas sobre las sexualidades y sus naturales encrucijadas.

Nuestra propuesta sobre la educación de las sexualidades es una opción para la formación de actores sociales plurales, que dispongan de recursos socio-cognitivos para construir sus nociones del mundo local y global, a partir de la confesión del propio cuerpo como mediación semiótica de las relaciones sociales en el fortalecimiento de la ciudadanía centrada en la civilidad, como valor social y práctica de tolerancia. Estos argumentos manifiestan retos a educadores y educadoras de distintas latitudes, especialmente la nuestra, porque estamos convocados a discernir sobre las sexualidades como un asunto cotidiano y encarnado en saberes socialmente productivos. Desde esta perspectiva, la educación de las sexualidades puede constituirse en el SEB, según los planteamientos propuestos a continuación:

- Desmitificar lo oscuro, lo peligroso, lo rígido, lo grotesco, lo feo, lo sucio y lo pecaminoso de algunos significados sexuales sobre el cuerpo.

- Descubrir los signos en las lógicas de vida propia de las personas, en función de sus edades y contextos culturales.

- Planificar la educación escolar con significados naturales, coherentes y consistentes con una visión crítica y reflexiva sobre las sexualidades y las relaciones humanas.

- Reconocer las fortalezas de las disciplinas científicas, sus fronteras permeables y áreas del conocimiento que contribuyen con la comprensión de las sexualidades, enfatizando la vida social.

- Considerar los significados sustantivos sobre las sexualidades que han sido excluidos y silenciados, buscando su reivindicación y considerándolos de igual importancia para entender el sentido humano de lo sexual en un mundo colectivo construido desde la interacción con la diferencia y lo diverso.

- Traspasar las barreras que oprimen y reprimen la concepción biológica de las sexualidades, permitiendo la superación de un enfoque sectorizado sobre lo sexual en el cuerpo físico de los seres humanos; entendiendo, pues, que somos cuerpos sociales cuyos atributos de civilidad, por naturaleza, hacen que nos mantengamos juntos en un estado de bienestar.

- Incorporar visiones gnoseológicas que trasciendan los discursos radicalmente morales, descontextualizados y destemporalizados sobre las sexualidades, persiguiendo concepciones plurales sobre la ética social de las prácticas ciudadanas.

- Considerar una visión y misión de la educación de las sexualidades sobre la base de imaginarios colectivos que orienten la emergencia de una pedagogía sexual centrada en lo humano, desde una perspectiva socio-histórica venezolana-y-latinoamericana, sin perder la conexión con el fenómeno mismo en su dinamismo global.

- Comprender los significados rectores determinantes en los roles de los diversos géneros sexuales, superando el sentido binario, saboteador y autodiscriminante para dejar emerger la participación de géneros que sociopolíticamente se están legitimando en las sociedades locales, entre ellas, la venezolana.

- Incorporar elementos culturales de la localidad donde conviven las personas, asumiéndolos como punto de referencia para el debate sobre las sexualidades; buscando además, la crítica-reflexiva, la contrastación y la validación social de los significados esenciales sobre las sexualidades como práctica libertaria de ciudadanía. 
- Destacar que los significados sobre las sexualidades en los seres humanos deben dejar de concentrarse en situaciones patológicas. En contraposición, debe enfatizar una re-valoración del cuerpo y de su funcionamiento desde lo sexual como un modo de armonización socio-ecológica.

- Subrayar que los significados sobre las sexualidades se configuran de manera transformadora, desde las semiósis sociales donde interactúan los seres humanos, obviando visiones individualizantes con tendencia al universalismo, la homogeneidad y el utilitarismo de los cuerpos sociales.

- Reconocer que la racionalidad teórico-metodológica que orienta la educación de las sexualidades se configura de elementos dinámicos, cambiantes y con facultad de re-elaboración-yrecursividad semiótica, factibles para las personas involucradas en el fenómeno educativo venezolano.

- Puntualizar que las sexualidades deben estar fundadas en significados que potencien el sentido de libertad de los seres humanos, evitando las intenciones reguladoras y supresoras de los discursos liberales provenientes de cualquier organización político-partidista.

- Señalar que las personas tienen experiencias subjetivas acerca de las sexualidades; asimismo, que todos son protagonistas en la construcción sociosemiótica de significados sexuales contemporáneos y contextualizados. Por tanto, todos nos constituimos como productores y reproductores de conocimiento sexual -popular y científico-, ante las sexualidades, lo que favorece que seamos legitimadores del sentido sexual que fundamenta las epistemes educativas.

Creemos que estas sugerencias servirán como orientación para la reflexión social de la educación de las sexualidades, que esperamos sean entendidas desde la vida, más allá de las linealidades pedagógicas que la han explicado por tanto tiempo. Pero, sobre todo, que sea practicada desde la tolerancia, el respeto y la dignidad democrática al ser actores con identidades sexuales corporizadas y vividas en la relación social. Para tales fines, convocamos a creer en una educación ampliamente democrática, reconociendo que nada es más estable, en el mundo que el cambio, la variación; así que, inventamos o erramos (Rodríguez, 2004).

\section{Notas}

1 Este trabajo es producto de las reflexiones producidas en el marco de las actividades académicas y de investigación desarrolladas en la Línea de Investigación Representaciones, actores sociales y espacios de poder, adscrita al Doctorado en Ciencias Humanas de la Facultad de Humanidades y Educación de la Universidad del Zulia. Además, surge de las discusiones desarrolladas con las estudiantes de la asignatura Educación Sexual (Períodos 2006 I y 2006-II) de la Licenciatura en Educación Especial del Núcleo Costa Oriental del Lago de la Universidad del Zulia (Venezuela).

2 En correspondencia con la noción de educación que asumimos en este trabajo, creemos que todos y todas, como actores sociales, enseñamos y aprendemos; pues, como tales, nos encargamos de la producción y reproducción cultura de los dispositivos de control inscritos en los discursos sociales y que circunscriben las agendas educativas vigentes. Sin embargo, lo central es considerar que somos aprendices y enseñantes que se recrean en la interacción social comunicativa develada en las cotidianidades, generándose una relación dialógica que favorece la construcción de saberes sociales.

3 Las disciplinas científicas, especialmente las asociadas con lo humano y lo social, se asumen como dispositivos de control; pues establecen criterios para la normalización de la vida social e individual mediante rigores producidos en el discurso ilustrado. Con ello, se asume que las personas se perciben como sujetos dóciles, ya que sobre estos recaen las direcciones de la ortopedia social. La 
constitución de la sociedad disciplinaria ha sido abordada amplia y sucintamente por Michel Foucault, argumentando que la docilización de los cuerpos es resultado de la constitución de las relaciones entre saberpoder. El filosofo francés, expone en su obra Vigilar y Castigar, que "es dócil un cuerpo que puede ser sometido, que puede ser utilizado, que puede ser transformado y perfeccionado" (p. 140); en suma, que puede ser objeto de sujeción.

Muy a pesar de los esfuerzos desplegados por el SEB, se observa que la práctica educativa en vías de transformación sigue apegada al sustrato ideológico de la educación neoliberal, individualista, arbórea y tecnocrática que ha predominado por más de cuarenta años en Venezuela, de la cual no se exceptúan los aspectos sobre lo sexual y la sexualidad.

Por ejemplo la pornografía, la exacerbación de la publicidad erótica, los "reality show", entre otros productos mediáticos que se constituyen como agentes de mediación de la vida sexual pública. Al respecto, Giddens (2004) señala la ruptura entre lo privado y lo público de la sexualidad, y por más que pretendamos ocultarla y silenciarla, esta dimensión humana busca aflorar por algún lado de los límites - permeables- de la cotidianidad. Lo importante es comprender las dinámicas sociales que dan cuenta de las prácticas simbólicosexuales, desencadenadas a propósito de los desafíos que se le presentan a las subjetividades. Para Vélez (2002), los mercados de expresiones se constituyen en escenarios donde se intercambian subjetividades mediante el diálogo, donde confluyen lo privado y lo público con sentido ascético y normalizador.

En Venezuela contamos con dos estudios importantes que orientan la construcción ontológica de la relación, a partir de evidencias empíricas locales. Moreno (1995) señala que la familia venezolana es matricentrada, estructura que actúa como nodo para establecer la naturaleza ontológica de los venezolanos y venezolanas, quienes, a decir del autor, somos comprensibles como relación viviente. Para la psicóloga venezolana Maritza Montero (2000), y siguiendo los supuestos epistemológicos fundados en la filosofía de la liberación desarrollada por Dussel y Levinas, la ontología de la relación "supera la exclusión al aceptar al OTRO en su otredad, en su distintividad, en su condición extraña, como un ser en plano de igualdad con el UNO, aunque desconocido" (p. 23; énfasis en el original).
Por tanto, la relación se entiende como "la conexión, correspondencia o asociación que existe entre las personas o entre las personas y las cosas" (p. 24), desvelando que el carácter social va más allá de la cantidad de unidades y se centra en las cualidades producidas en la interdependencia socio-cultural salida de la interacción.

$7 \quad$ El signo se establece como parte estructural de un tipo de performatividad orientada a la sacralización banal de la figura corporal, por ende, de la subjetivación de las identidades sexuales en lo social, educativo, familiar, así como en otras dimensiones; las cuales, enfatizan un modo de index appeal que implica el crecimiento constante de los significados, lo que ocurre cada vez que la realidad es representada y produce órdenes hegemónicos de interacción que, por no depender de la interpretación de los hechos, conlleva un efecto táctil sobre la presencia del otro en acto de alteridad (Andacht, 2005, a, b).

\section{Referencias bibliográficas}

Acker, S. (2000). Género y educación. Reflexiones sociológicas sobre mujeres, enseñanza y feminismo. Madrid: Editorial Narcea.

Amado, A. y Domínguez, N. (1998). Presentación. En D. Balderston y D. Guy, (Comps.). Sexo y sexualidades en América Latina. México: Ediciones Paidós.

Andacht, F. (2005a). Elementos semióticos para abordar la comunicación visual e indicial de cada día. En Asociación Venezolana de Semiótica: Semióticas audiovisuales. Colección de Semiótica Latinoamericana Nos. 2 y 3 (pp. 33-54). Maracaibo: En Asociación Venezolana de Semiótica.

Andacht, F. (2005b). La reflexividad mediática en el género indicial documental. Enlace. Revista venezolana de información, tecnología y conocimiento, 2(3), 75-92. 
Bernstein, B. (1998). Pedagogía, control simbólico e identidad. Teoría, investigación $y$ crítica. España: Ediciones Morata.

Beyer, L. y Liston, D. (2001). El curriculum en conflicto. Perspectivas sociales, propuestas educativas y reforma escolar progresista. España: Ediciones Akal.

Butler, J. (2006). Gender trouble. Feminism and the subversion of identity $[E l$ género en disputa. Feminismo y la subversión de la identidad]. New York: Routledge Classics.

Carnoy, M. (1977). La educación como imperialismo cultural. España: Siglo XXI.

Castro-Gómez, S. y Grosfoguel, R. (2007). Prólogo. Giro decolonial, teoría crítica y pensamiento heterárquico. En S. Castro-Gómez y R. Grosfoguel (Eds.), El giro decolonial. Reflexiones para una diversidad epistémica más allá del capitalismo global (pp. 9-23). Bogotá: Siglo del Hombre Editores.

Chomsky, N. (2002). La (des)educación (2 $2^{\mathrm{a}}$ ed.). Barcelona: Editorial Crítica.

Díaz, M. (2005). Educación inicial. Educación de la sexualidad, salud reproductiva y equidad de género. Gobierno Bolivariano de Venezuela. Caracas: MSDS-MED.

Dussel, E. (1999). Me llamo Rigoberta Menchú y así "me nació la conciencia”. En U. Klesing-Rempel (Comp.) y A. Knoop (Coord.). Lo propio y lo ajeno. Interculturalidad y sociedad multicultural (pp. 125-152). México: Plaza y Valdés Editores.

Elias, N. (2000). La sociedad de los individuos. Ediciones Península. Barcelona.
Foucault, M. (1992). Microfísica del poder (3 ed.). Madrid: Ediciones La Piqueta.

Foucault, M. (1996). La vida de los hombres infames. Argentina: Editorial Altamira.

Foucault, M. (1999). Vigilar y castigar. El nacimiento de la prisión (29 $9^{\mathrm{a}}$ ed.). México: Siglo Veintiuno Editores.

Foucault, M. (2003). La ética del cuidado de sí como práctica de libertad. En C. Gómez (Ed.), Doce textos fundamentales de la ética del siglo XX. El libro de bolsillo (pp. 256-264). Madrid: Alianza Editorial.

Foucault, M. (2004). No al sexo rey. Entrevista por Bernard Henry-Levy. En M. Foucault, Un diálogo sobre el poder $y$ otras conversaciones $\left(1^{\mathrm{a}}\right.$ Reimpresión) (pp. 157-173). Madrid: Alianza Editorial.

Foucault, M. (2006). Historia de la sexualidad 1: La voluntad de saber (1 ${ }^{\mathrm{a}}$ Reimpresión de $10^{\mathrm{a}}$ ed.). España: Siglo XXI Editores.

Freire, P. (1996). Pedagogía del oprimido (47ª ed.). México: Siglo XXI Editores.

Garcés, M. (2005). La vida como concepto político: Una lectura de Foucault y Deleuze. Athenea Digital, 7, 87-104. Consultado el 14 de junio del 2005 de http://antalya.uab.es/athenea/num7/ garces.pdf

García, C., Cabral, B., Monsalve, N. y Alarcón, J. (2003). Sexismo en el aula de preescolar. Mérida: Universidad de Los Andes, Consejo de Publicación.

Giddens, A. (2004). La transformación de la intimidad. Sexualidad, amor y erotismo en las sociedades modernas (4ª ed.). Madrid: Ediciones Cátedra. 
Hill, D. (2007). Educación crítica para la justicia económica y social: Un análisis y manifiesto marxista. En L. Huerta-Charles y M. Pruyn (Coords.). De la pedagogía crítica a la pedagogía de la revolución. Ensayos para comprender a Peter McLaren (pp. 210-253). México: Siglo XXI Editores.

Lander, E. (2000). Ciencias sociales: Saberes coloniales y eurocéntricos. En E. Lander (Ed.), La colonialidad del saber: Eurocentrismo y ciencias sociales (pp. 11-58). Caracas: Ediciones FACES-UCV.

Leistyna, P. (2007). Las posibilidades revolucionarias del desarrollo profesional multicultural en las escuelas públicas. En L. Huerta-Charles y M. Pruyn (Coords.) De la pedagogía crítica a la pedagogía de la revolución. Ensayos para comprender a Peter McLaren (pp. 117-146). México: Siglo XXI Editores.

Louro, G. (2001). Teoria queer-Uma política pós-identitária para educação [Teoría Queer - Una política postidentitaria para la educación]. Estudios Feministas, 2, 541-553.

Maffesoli, M. (2005). El conocimiento ordinario. Compendio de sociología (1 $1^{a}$ Reimpresión). México: Fondo de Cultura Económica.

Maturana, H. (2002). Emociones y lenguaje en educación y política ( $11^{\mathrm{a}}$ ed.). España: Dolmen Ediciones.

McLaren, P. (2001). El Che Guevara, Paulo Freire y la pedagogía de la revolución. México: Siglo XXI Editores.

McLaren, P. y Jaramillo, N. (2006). Pedagogía y praxis en la era del imperio. Hacia un nuevo humanismo. España: Editorial Popular.
Mignolo, W. (2007). La idea de América Latina. La herida colonial y la opción decolonial. Barcelona: Editorial Gedisa.

Montero, M. (2000). El sujeto, el otro, la identidad. Avademos, 2(2), 11-30.

Montero, M. (2002). Construcción del otro, liberación de sí mismo. Utopía y Praxis Latinoamericana, 7(16), 41-51.

Moreno, A. (1995). El aro y la trama. Episteme, modernidad y pueblo $\left(2^{\mathrm{a}}\right.$ ed.). Caracas: CIP.

Pérez, C. (2008). La convivencia social como proyecto político colectivo. Utopía y Praxis Latinoamericana, 13(42), 107-129.

Pérez, C. y Vázquez, B. (2006). Ser-y-saber docente para una práctica educativa. Revista Venezolana de Ciencias Sociales, 10(2), 369-392.

Pérez de Lara, N. (2000). Masculinofemenino en educación especial. En M. Téllez (Comp.), Repensando la educación en nuestros tiempos. Otras miradas, otras voces (pp. 71-94). Buenos Aires: Ediciones Novedades Educativas.

Rodríguez, S. (2004). Inventamos o erramos. Caracas: Monte Ávila Editores Latinoamericana.

Sierra, C. (2002). El aprendizaje de los roles de género: De la inferioridad intelectual a la igualdad curricular. En M. L. Abad et al. Género y educación. La escuela coeducativo. Colección: Claves para la innovación educativa, 15 (pp. 13-22). Caracas: Laboratorio Educativo

Silva, T. (2001). Espacios de identidad. Nuevas visiones sobre el currículum. Barcelona: Ediciones Octaedro. 
Spargo, T. (2004). Foucault y la teoría queer. Barcelona: Editorial Gedisa.

Valera-Villegas, G. (2002). Pedagogía de la alteridad. Caracas: Colección Monografías. Comisión de Estudios de Postgrado, FHE-UCV.

Vázquez, B. (1999). Representaciones, actores sociales y espacios de poder desde el enfoque interdisciplinar. Fermentum, 24, 35-57.

Vázquez, B. (2005). Del ciudadano en la nación moderna a la ciudadanía nacionalista. Utopía y Praxis Latinoamericana, 10(31), 63-78.

Vélez, M. (2002). Un intercambio simbólico de identidad y alteridad. Universitas Humanistica, 53, 33-47.

Venezuela, Ministerio del Poder Popular para la Educación [MPPE]. (2007). Diseño curricular del sistema educativo bolivariano. Caracas: Fundación Imprenta Ministerio del Poder Popular para la Cultura.

Wallerstein, I. (2005). Las incertidumbres del saber. Barcelona: Editorial Gedisa. 
